6. Софронова В.В., Никулина Л.П. Организация самостоятельной работы студентов в языковом вузе / В. В. Софронова, Л. П. Никулина // [Электронный pecypc] - Режим доступа: https://cyberleninka.ru/article/n/organizatsiyasamostoyatelnoy-raboty-studentov-v-yazykovomvuze-1 (дата обращения 15.01.2020)

7. Федосеева О.Ю. Анализ эффективности самостоятельной работы студентов с использование информационных технологий /
О.Ю. Федосеева // [Электронный ресурс]. - Режим доступа: https://cyberleninka.ru/article/n/analizeffektivnosti-samostoyatelnoy-raboty-studentov-sispolzovaniem-informatsionnyh-tehnologiy (дата обращения 15.02.2020)

8. Taibi D., Chawla S., Dietze S., Marenzi I., \& Fetahu B. Exploring TED talks as linked data for education. British journal of educational technology № 46(5), 2015. - 1092-1096 p.

https://orcid.org/0000-0002-9935-0750

УДК 355.23

ГРНТИ 14.35.07

ЛИЧНОСТЬ ГЕНЕРАЛА - КАК ОБРАЗ НАЦИОНАЛЬНОГО ДУХА

DOI: 10.31618/ESU.2413-9335.2020.8.74.785

Кожануль Манасбай

к.ф.н., профессор.,

Рыскульбеков Айдын Истаевич

PhD., дочент кафедры военной истории и права.,

Тогусова Алтын Каликановна

к.и.н., ассочиированный профессор.

Национальный университет обороны имени

Первого Президента Республики Казахстан - Елбасы,

2. Нур-Султан, Казахстан

\title{
THE GENERAL'S PERSONALITY - AS AN IMAGE OF THE NATIONAL SPIRIT
}

\begin{abstract}
АННОТАЦИЯ
В данном научном труде исследована значения проблемы личности генералов в направлении мировой военной науки, в том числе личности/индивидуализации казахстанских генералов. В ходе исследования, опираясь на методы индуктивные и дедуктивные, суждения личности казахских генералов, критическое мышление, прогноз-анализ и эвристические и т.д., социологические, психологические и социальные измерения в становлении личности человека показано,что социальный критерий играет ведущую роль в обретении индивидуализма. В результате исследования были определены общие принципы личности генералов как фактора путей военно-патриотического воспитания молодежи из условно полученного графика на основе влияния условий внешней среды на пути роста до звания генерала, простого человека и военного человека, а также из результатов написания эссе, проведенного в соответствии с темой.

\section{ABSTRACT}

This scientific work examines the significance of the problem of the personality of generals in the direction of world military science, including the personality/individualization of Kazakh generals. In the course of the study, based on inductive and deductive methods, judgments of the personality of Kazakh generals, critical thinking, forecast-analysis and heuristic, etc., sociological, psychological and social dimensions in the formation of a person's personality, it is shown that the social criterion plays a leading role in the acquisition of individualism. The study identified some common principles of individual generals as a factor in ways of military-patriotic education of youth from probation received graphics based on the impact of environmental conditions on growth to the rank of General, common man and military man, as well as the results of essay writing, conducted in accordance with the theme.

Ключевые слова и словосочетание: военные науки, личность, изучение личности, военный дух, личность казахстанского генерала, патриотизм.

Keywords and phrases: military sciences, personality, study of personality, military spirit, personality of Kazakhstan general, patriotism.

\section{Введение.}

C развитием той или иной отрасли науки в обществе, безусловно равиваются и разветвляются и его внутренние подотрасли. В сфере мировых общественных наук одна из них - проблема изучения личности генералов. Актуальной проблемой является формирование и комплексное исследование научной школы личности генералов, в том числе казахстанских генералов, опираясь на

взгляды ученых - исследователей о проблеме личности.

В ходе обзора литературы, связанной с материалами исследования, были изучены особенности личности в эпоху глобализации и важность организации управления деятельностью в коллективе, обучающихся в системе мирового образования зарубежного авторы П. Стивен, А. Тимати «Основы поведения организации» [1] Глава
\end{abstract}


4 заложена критерий в основу проблемы исследования.

Обзор литературы.

Проблему познания личности изучали еще с древнейших времен, еще до нашей эры, практически все выдающиеся ученые энциклопедисты, но преимущественно этим занимались ученые, положившие начало основанию своих школ в педагогике и психологии.

Авторы педагогического учебников для вузов $[2 ; 3 ; 4 ; 5 ; 6]$, использованного в ходе исследования данную проблему рассматривают ученые: Э. Геккель, Ф. Мюллер, И. Шванцара, П.П. Блонский, А.С. Выготский, С.Л. Рубинштейн, В.А. Сластенин, Д.В.

Ельжанов,

К. Сейталиев, 3. Байжанова, Б. Айтмамбетова, А. Бейсенбаева и др. Эти ученые исследователи изучают проблему познания личности, ее развитие и становление без отрыва от внутренних и внешних факторов - все это рассматривается прежде всего в аспектах таких наук как педагогика и психология. Также автор этой статьи [7], опираясь на взгляды выше перечисленных ученых, обращает внимание, что тем не менее социология рассматривает проблему познания личности прежде всего в аспекте изучения роли субъекта (человек/личность/индивид), отражающего совокупность соответствующих общественных отношений.

Во многих научных аспектах проблема личности достаточно широко изучена, но главная новизна данного научного исследования в том, что личность генерала рассматривается - как фактор военно-патриотического воспитания.

В проведении исследования используются авторские схемы, показывающие карьерный рост военного человека в ходе формирования личности казахстанского генерала. Полученные в результате исследования теоретические и практические выводы помогут осветить роль личности в формировании образа национального духа.

Первый Президент Республики Казахстан Н.А. Назарбаев в своем послании народу Казахстана «Казахстанский путь - 2050: «Единая цель, единые интересы, единое будущее», провел ретроспективные и перспективные обозрения судьбы многонационального народа Казахстана. В Послании обозначена трех ступенчатая платформа «Цель, интересы, будущее», которая практически олицетворяет нынешний облик кадрового офицера военной службы, преданно и честно служащего своей родине, верного своей клятве перед народом.

Материалы и методы исследования.

Развитие науки пополняется новыми данными. А в процессе их изучения, начиная с традиционных педагогических методов, потребуются методы педагогических исследований, основанные на новейших современных технологиях. В ходе исследования было предусмотрено дальнейшее развитие метода критического мышления в личностном направлении, основываясь на методах обобщения и осмысления собранного материала. По данному вопросу интересующиеся статьи могут опираться на другие источники, которые хотят более глубоко знать (Bower \& Hilgard, 1981; Heidbreder, 1993; Hunt, 1993) [1, 21 c.; 3, c. 31-56.; 6, c. 92-95].

Как известно, метод в направлении личностного развития осуществлялся в 70-е годы в США, Европе в рамках гуманистической педагогики, свободного воспитания и др., а в 80-е годы в рамках педагогики сотрудничества в Советском Союзе. Метод развития общечеловеческого направления заключается в том, чтобы помочь человеку в саморазвитии, в критическом отношении, сформировать новое сознание и самосознание.

Когда-то великий Абай так писал о человеке как о личности:

«...от таких вещей подальше держись,

... и к таким вещам стремись.

... Если хочешь стать человеком» $[8$, с. 21].

Тем самым великий поэт предостерегал от опрометчивых шагов молодых людей, указывая основные элементы становления личности, а также ведет речь о качествах, необходимых для становления креативной личности, в том числе о социальной ответственности личности перед обществом.

В словаре приведено следующее определение:

«Личность - 1) это отдельно взятый конкретный человек, действующий индивидуально как субъект; 2) отдельный представитель человеческого рода, общества, осознающий свою индивидуальность и ответственность» [9, с. 539540].

В зарубежной литературе пишется: «Личность - совокупность способов восприятия и взаимодействия с другими человека» [1, с. 82].

Также можно найти в интернете: «Личность не только естественно-биологические качества человека, а единство билогических, психогенных, социогенных свойств, определяющих его поведенческую, ролевую деятельность в обществе, сущность человека, преломленных в личности как совокупности общественных отношений. Практически, является началом социальной сущности человека. Одним словом, личность социальное явление, отражающее сущность человека как индивида, преломленных в человеке в процессе развития как личности» [10].

Кроме того имеется следующее определение: «Личность - индивид, ставший личностью в процессе его включения в систему общественных отношений порседством активной деятельности и общения.

Основное качество личности - его социальная сущность, так как индивид становится личностью в процессе освоения социальных функций и развития самосознания.

Наиболее важные свойства личности осознание своей роли в системе общественных отношений, ответственности, усвоение ценностей общественных отношений, не теряя при этом своей индивидуальности. 
Личность - совокупность социально значимых качеств человека, ведущего активную общественную деятельность.

Индивид - это отдельный, обособленный член социальной общности. Если понятие «личность» используется для исследования социальных качеств человека, свойственных многим людям, то понятие «индивид» в социологии употребляется для того, чтобы выделить социальные качества конкретного человека.

«Индивид обладает бесчисленным множеством социальных структур» [11]. Индивидуальность - высшая степень развития личности, практически «индивидуальность» означает уровень социализации и включения индивида в социальную жизнь общества. Индивидуальность - высокий уровень синтеза многогранной личности, глубоко интегрированного в социальной структуре [9, с. 216].

Следуя вышеприведенным определениям, они не только соприкасаются с мыслью великого Абая, но и сочетаются с тем, что каждый гражданин, в том числе и личность казахстанского генерала, их биографии, пройденным жизненный путь, сравнивая их карьерную лестницу, умение накапливать знания, опыт работы, в том числе усвоенные социальные нормы, ценности, стандарты поведения, определяю их уровень социализации и включения как индивида в социальную жизь общества.

Методы исследования.

Человек личностью не рождается, он ею становится в процессе своей жизнедеятельности. Как доказано в науке, в связи с развитием личности (З.Фрейд, А. В. Петровский, А. В. Мудрик и др.) являясь биологическим организмом, человек обладает кроме биологических, еще и психилогической сущностью, социальными качествами. Социология рассматривает человека прежде всего как социальное явление социальную сущность. Социология изучает личность с точки зрения ее включенности в общество, в общественные отношения и формирования у человека особенных личностных качеств под влиянием социальной среды.

Очевидно, что человек на протяжении всей жизни формирует и изменяет свое сознание, социализируется, приобретая все новые социальные качества, развиваясь и совершенствуясь. Именно поэтому, учитывая, что исходя из новых технологических методов в направлении личностного развития социальная адаптация представляет собой приспособление индивида к социальной среде, а также интегрирование - процесс вхождения во внутренний мир человека ценностей, социальных правил, законов, норм.

Выделим некоторые особо важные факторы в становлении личности кадровых офицеров (генералов). Например, люди, в том числе кадровые офицеры на протяжении всей жизни включены в бесчисленное количество социальных групп и, взаимодействуя, испытывают их социализирующее влияние и социализирующее влияние общества в целом. Вместе с тем, личность активно влияет на социальную и природную среды своего существования, активно преобразуя их соответственно своим потребностям. Поэтому, факторы в становлении личности кадровых офицеров (генералов), в том числе факторы на основе влияния внешних обстоятельств на пути роста обычного человека можно увидеть условно взятую ниже таблицу (Таблица 1):

В нижеприведенной таблице данные факторы отражены:

1-таблица:

Пути становления личности

\begin{tabular}{|c|c|c|}
\hline \multirow{2}{*}{ Пути обычного человека } & \multicolumn{2}{|c|}{ Кадровый военный путь } \\
\hline & Должность & Военный чин \\
\hline учеба//рабочий & Окончил обучение & лейтенант \\
\hline $\begin{array}{c}\text { специалист/переквалифика-ция по } \\
\text { специальности }\end{array}$ & \multicolumn{2}{|c|}{ Служба по специальности/должность } \\
\hline $\begin{array}{c}\text { Государственная/не государственая } \\
\text { организация - служащий }\end{array}$ & $\begin{array}{c}\text { командир взвода; } \\
\text { заместитель } \\
\text { командира роты. }\end{array}$ & $\begin{array}{l}\text { лейтенант; } \\
\text { ст. лейтенант; } \\
\text { капитан. } \\
\end{array}$ \\
\hline $\begin{array}{c}\text { Государственная/не государственая } \\
\text { организация - начальствующий состав }\end{array}$ & $\begin{array}{c}\text { командир батальона; } \\
\text { заместитель командира } \\
\text { бригады } \\
\end{array}$ & $\begin{array}{c}\text { майор; } \\
\text { подполковник, } \\
\text { полковник. } \\
\end{array}$ \\
\hline $\begin{array}{c}\text { - директор (завода, комбината, компании } \\
\text { и т.д.) }\end{array}$ & \multirow{4}{*}{\multicolumn{2}{|c|}{$\begin{array}{c}\text { Служебные должности - воинская служба (условно): } \\
\text { - начальник (управления, департамент } \\
\text {.); командующий региональным командованием; начальник } \\
\text { штаба - заместитель - министра;- министр }\end{array}$}} \\
\hline Аким аула, села & & \\
\hline Руководитель города, района & & \\
\hline Руководитель области & & \\
\hline
\end{tabular}

\section{Результаты исследований.}

Как видно из таблицы, в результате анализа темы, «личность - служба и личность организации» [1, c.100] личности (человек/начальник) при достижении ими поставленной цели, условно подразделить можно на 4 типа и 3 карьерных ступени кадров офицерского состава. Личность условно разделим на 4 типа:

a) упорное преследование предназначенной 
цели;

б) подчинение цели предназначенной ценностной ориентации;

в) подчинение цели предназначенным общим интересам (аффективный интерес);

г) подчинение цели духовным национальным интересам (в том числе традициям).

Личности всех 4 типов (человек) далее ориентируются на:

- внешнее восприятие общества (среды);

- в том числе на оценку своеего внешнего вида обществом (средой);

- смог-ли я соответствовать требованим общества (среды).

Личность (человек) успешно прошедший через 3 этапа, сумевший построить себе необходимый положительный имидж, как правило, успешно продвигается по служебной лестнице. Следовательно, всем этим личностям присущи такие общие черты (здесь, имеются ввиду офицеры, начальствующий состав):

- умение принимать оптимальные решения в рамках служебной компетенции, не нарушая воинский устав и этику, оперативно реагируя на ту или иную создавшуюся внештатную ситуацию;

- при доведение приказа сверху вниз умение четко давать команду, сформулируя их предельно точно (приказы точные, четкие, ясные);

- исполнение заданий совершенно четко, без волокиты, формируя их кратко, содержательно и в доступной форме;

- образование, уровень мышления, умение говорить, культура поведения, все в офицере должно быть образцово, подчеркивая гармонию внешнего и внутреннего мира;

- образование и культура поведения, все должно свидетельствовать о высоком уровне индивидуальности офицера как высоко развитой личности;

- сформировавшаяся личность офицера, в результате полной адаптации к выдывигаемым требованиям среды;

- профессия, служебная должность соответствие личности его статусу, следовательно, офицер вышколен, вымуштрован в надлежащей мере, а потому полностью соответствует своему статусу (в обществе).

Как уже было отмечено выше, при формировании казахских офицеров - высшего состава генералитета, прошедшего все ступени, бывшие курсанты, ставшие генералами (генералармии С.К. Нурмагамбетов; генерал-полковники А.Х. Касымов, С.Б. Токпакбаев; генераллейтенанты

М.М. Сапаров, Р.Ф. Жаксылыков, Н.Н. Поспелов; генерал-майоры

А.Б. Джарбулов, М.К. Даиров), а также вернувшиийся на родину из Монголии бригадный генерал Ж. Халидолда и многие другие [12], прошедшие школу офицерского состава в военных школах и училищах) все они в результате безупречной военной службы прошли через все ступени военной карьеры, накапливая опыт офицерской военной службы долгие годы беспрестанного труда, беспристрастной и честной службы родине - Республике Казахстан за счет упорства, преданности выбранной профессии, не смотря на все трудности и тяготы отнюдь не легкой профессии. У них у всех были общие принципы. Вот они эти принципы:

-порядок (железная военная дисциплина, чистота помыслов в службе, высокая культура);

-политика (формирование среды дружеских отношений без панибратства;

-кадры (профессиональное образование, опыт, накопленный за долгие годы службы);

-свойства (трезвый ум и высокий уровень образования, четкая система мышления, гибкая дипломатия, предусмотрительность и дар предвидения, стратегия мышления);

-грамотно поставленная речь (культура речи, четкий командный голос);

-взаимоотношения (свободный обмен мнениями соблюдая чистоту помыслов);

-эксперты (вежливые партнерские взаимоотношения с соблюдением приоритета интересов коллектива);

-признание (беспрекословно полное признание их авторитетов);

-поведение

(беспристрастность, отстраненность от эмоций);

-взаимопомощь (помощь нуждающимся, паритетное соблюдение общих интересов, ситуационное взаимопонимание);

-приказы (должны быть четкми, точными, совершенно ясными);

-задания (совместный анализ исполнителями, принятие общих решений);

-надзор (наблюдение своевременного исполнения заданий);

-анализ (системный обмен мнениями, сообщений и информации, при анализе подробное иложение всех аспектов вопросов);

- сбор (всемерное обсуждение вопросов со всех сторон, системный взгляд, проецирование всех имеющихся мнений, умение руководителя четко подытожить, резюмировать вопросы, обстоятельное обсуждение всех участников);

-вblводы (умение принять окончательное взаимовыгодные решения, устраивающие обе стороны).

Генералы страны являются высшими военными чинами, цветом офицерства. Следовательно, во-первых, мы должны помнить прежде всего, что сказал в своем выступлении Елбасы Н.А. Назарбаев: «Основные цели политики - интересы народа, общества, человека» [13, с. 52].

Если эти слова принять за основу в контексте службы военных руководителей генералы, защищающих родину, то их следует понимать 
следующим образом: «Цели военных руководителей генерала - человек - общество интересы народа», а во-вторых, характеризуя личности генералов, как полностью сформировавшихся индивидиумов, следует резюмировать словами великого Абая:

«Не верь никому, как бы тебя ни хвалили,

Все льстецы чего бы тебе ни сулили,

Самому себе только ты поверь.

Лишь ум и труд выручат теперь» [8, с. 88].

О духе военного мышления казахстанских генералов, мы можем сказать, что все они преданные клятве перед народом Казахстана, настоящие профессионалы, достигшие успехов, благодаря личностным качествам и за счет упорного труда, а также глубокого ума. Считаю, что все генералы Казахстана обладают данными личностными качествами.

Благодарим ученого, кандидата военных наук, ассоциированного профессора А.А. Мартынова за помощь в дополнении рукописи полезными материалами по военно-патриотическому воспитанию и оценки роли личности в истории.

Статья написана в рамках выполнения грантового проекта на 2018-2020 годы «Совершенствование системы военнопатриотического воспитания студенческой молодежи на военных кафедрах высших учебных заведении Республики Казахстан».

Заключение.

Как уже было утверждено в ходе исследования и из предложенной выше таблицы следует, что все тесно связно в действия человека, в том числе их личности отличают: любовь к родине, гуманизм, верность традициям и родине, а также идеология государства Республики Казахстан. Один только пример из жизни: достаточно красочно и ярко иллюстрирует данные качества личный пример Елбасы Н.А. Назарбаева. Его жизнь и деятельность, практически идеальный образец служения долгу и преданности народу Казахстана. Его постоянный беспрестанный личностный рост обусловил становление Елбасы как уникального вождя, вышедшего из среды представителей простого народа (он начинал свою трудовую деятельность как простой рабочий, прошел долгий путь становления как уникальной личности: иех, завод, комбинат, город, руководитель областного масштаба, а затем карьера на высшем уровне руководства республики [13, с. 28]. Помимо этого, Елбасы стал лидером мирового масштаба, путь пройденный им в жизни исключительно достойный пример для всех, прежде всего для молодежи. Историческая личность, сотворивший новую историю Казахстана, как суверенного государства, деяния мирового масштаба, его труды давно стали общностью мировой сокровищницы, его духовное наследие будут сохранены на века, а также станут фундаментом создания новой науки: познания личности, что является новым особым вкладом в отечественную науку.

$B$ заключение хотелось бы сказать следующее: весь карьерный путь казахских генералов, прошедших все ступени карьерного роста, свидетельствует об их приверженности идее честного и преданного служения народу Казахстана, на основе их фанатической честности и высочайшего уровня профессионализма следует сформировать дух казахстанского патриотизма и создать фундамент научной школы познания личности казахстанских генералов.

В связи с этим, приведем высказывание исследователя Г.С. Исаевой: «Вне зависимости от того, к какой социальной прослойке человек принадлежит, как и любому другому живому организму, человеку изначально присущи гносеологические способности. Люди друг от друга отличаются лишь внешними признаками» $[14$, с. 53].

Следовательно, каждый человек в процессе непрерывного роста и становления своей личности, тщательно вбирает в себя накопленный опыт предыдущих поколений, растет не только по ступеням карьерного роста, но и создает себя как неордирнарную личность (человек - рабочий, специалист, служащий и руководитель, или военный - командир отделения, взвода, роты, батальона и бригады, заместитель, руководитель государственного органа и т.д.), даже если они друг от друга отличаются лишь внешними признаками, личностный рост возможен только лишь при наличии особого духовного мира, их внутрениий мир обогащается не только за счет познания внешнего мира, но и в общем процессе развития как личности. Одним словом, личностный рост казахстанских генералов позволяет им стать гордостью не только всей нации, но и определяет их самосознание как офицера, кадрового военного специалиста, чей внутрениий мир безбрежен и намного глубже, чем это может показаться на первый поверхностный взгляд иных людей. Генералы - гордость нашей отечественной военной истории, их ежедневный беспрестанный труд в Вооруженных Силах страны не заметен на первый взгляд. Специалистам разных научных отраслей: гуманитариям, общественникам, а также представителям военной науки еще предстоит заняться исследовательской работой - основанием фундамента познания личности офицеров казахстанских генералов.

\section{СПИСОК ЛИТЕРАТУРЫ:}

1 Essentials of Organizational Behavior, Fourteenth edition. Стивен Р., Тимати А. Основы поведение организации, 14-изд. - Алматы: общественный фонд «Бюро национального перевода», 2019. - 488 с (на каз.яз.).

2 Сорокопуд Ю.В. Педагогика высшей школы. Ростов-на-Дону. Феникс, 2011. - 541 с.

3 Военная педагогика и психология /А.В. Барабанщиков, В.П. Давыдов, Э.П. Утлик, Н.Ф. Феденко. - М.: Воениздат, 1986. - 240 с. (Библиотека офицера).

4 Ельжанов Д. В., Имиров С. К., Мухамедина Э. Д. Военная педагогика. Педагогический 
практикум: Учебное пособие. - Петропавловск, 2017. - 304 с. ил.

5 Сейталиев К. Общие основы педагогики. Учеб. пособие. - А.: Эксмо, 2009. - 232 с.

6 Байжанова 3. Общая педагогика. Учеб. пособие. - Алматы: Таймас, 2008. - 168 с.

7 Кожанулы М. Личность (человека) роль в формировании понятия аксиологии// «Ориентир» журнал, №2 (66) июнь, 2015. - 45-48 с.; Патриотизм - один из факторов формирования личности (человека)//Кн.: «М.К. Алтынбаев: путь генерала: годы чести и достоинства» Сборник материалов НПК (25.11.2015 г.). Кокшетау, 2015. - 103-107 с. (соавт. С. Молдабаев, Т. Сембинов) (на каз.яз.).

8 Кунанбаев А. Стихи. - А., 1987. - 159 с (на каз.яз.).

9 Жарыкбаев К.Б., Сангылбаев О.С. Психология: Энциклопедический словарь. А., 2011. - 624 с (на каз.яз.).

10

http://testent.ru/load/studentu/sociologija/t_1_a_ymyn y_m_ni_men_t_sinigi/50-1-0-1081 (на каз.яз.) (дата обращения - 15.04. 2018 г.).

11 http://sacok.kz/referat/show/707 (на каз.яз.) (дата обращения - 15.04. 2018 г.).

12 Генералы Казахстана. Библиографический справочник. - Алматы: Изд-во «Арыс», 2006. - 400 с. +16 с. цвет. ил.

13 Кекилбаев А. Елбасы //Кн.: Размышления о личности. - А., 2011.- 440 стр (на каз.яз.).

14 Исаева Г.С. «Лингвоаксиологичесике особенности концептов «разумность и глупость»// Научно-педагогический журнал «Білім». - 2013 № 3. - 53-58 с (на каз.яз.).

\section{REFERENCES}

1 Essentials of Organizational Behavior, Fourteenth edition. Steven R., Timati A. Fundamentals of organizational behavior, 14-ed. - Almaty: public Fund «National Bureau of translation», 2019. - $488 \mathrm{p}$ (kaz. lang).

2 Sorokopud Yu. V. Pedagogy of higher school. Rostov-on-don. Phoenix, 2011. - 541 p (rus.lang).
3 Military pedagogy and psychology /A.V. Drummers, V.P. Davydov, E.P. Utlik, N.F. Fedenko. Moscow: Voenizdat, 1986. - 240 p. (Officer's library) (rus. lang).

4 Elzhanov D.V., Imirov S.K., Mukhamedina E.D. Military pedagogy. Pedagogical workshop: Teaching manual. - Petropavlovsk, 2017. - 304 p. (rus. lang).

5 Seitaliev G. General basics of pedagogy. Studies'. stipend. - Almaty: Eksmo, 2009. - 232 p. (kaz. lang).

6 Bayzhanova Z. General pedagogy. Studies'. stipend. - Almaty: Taimas, 2008. - 168 p (kaz. lang).

7 Kozhanuly M. Personality (human) role in the formation of the concept of axiology/ / «Landmark» journal, no. 2 (66) June, 2015. - 45-48 p. (kaz.lang); Patriotism - is one of the factors in the formation of a person (human).// Kn.: «M.K. Altynbayev: the way of the General: years of honor and dignity» Collection of materials of the NPK (25.11.2015). Kokshetau, 2015. 103-107 p. (joint authors.: S. Moldabaev, T. Sembinov) (kaz. lang). lang).

8 Kunanbayev A. Poems. - A., 1987. - 159 p (kaz.

9 Zharikbaev K.B., Sagynbaev O.S. Psychology: an Encyclopedic dictionary. A., 2011. - 624 p (kaz. lang).

10

http://testent.ru/load/studentu/sociologija/t_1_a_ymyn y_m_ni_men_t_ sinigi/50-1-0-1081 (kaz. lang) (accessed - 15.04. 2018).

11 http://sacok.kz/referat/show/707 (kaz. lang) (accessed - 15.04. 2018 г.).

12 Generals Of Kazakhstan. Bibliographic reference book. - Almaty: Arys publishing House, 2006. - 400 p. + 16 s. color. Sludge (rus. lang).

13 Kekilbaev A. The President //Kn.: Reflections on personality. - A., 2011.- 440 p (kaz. lang).

14 Isaeva G.S. «linguo-Axiological features of the concepts «reasonableness and stupidity»// Scientific and pedagogical journal «Bilim». - 2013. No. 3. - 53$58 \mathrm{p}$ (kaz. lang).

УДК: 372.893, ГРНТИ: 14.25.09

\title{
ТРАНСФОРМАЦИЯ МЕТОДИЧЕСКИХ ПОДХОДОВ К ИЗУЧЕНИЮ ИСТОРИЧЕСКОЙ ЛИЧНОСТИ И.В. СТАЛИНА В УЧЕБНИКАХ ИСТОРИИ: ОТ КУЛЬТА ЛИЧНОСТИ ДО НАСТОЯЩЕГО ВРЕМЕНИ
}

\author{
DOI: $10.31618 /$ ESU.2413-9335.2020.8.74.786 \\ Кудрявцев Владислав Юрьевич \\ обучающийся магистратурь \\ исторического факультета ФГБОУ ВО \\ «Курский государственный университет», г. Курск
}

\section{АННОТАЦИЯ:}

В данной статье рассматривается динамика методических подходов к изучению исторической личности И.В. Сталина, трансформация отражения изучения данного материала в учебниках истории для общеобразовательных организаций. Анализируется содержание учебников истории разных исторических периодов для обучающихся старшего школьного возраста. Обозначаются ключевые аспекты формирования у обучающихся представлений об исторической личности И.В. Сталина.

\section{ABSTRACT:}

This article discusses the dynamics of methodological approaches to the study of the historical personality of I.V. Stalin, the transformation of the reflection of the study of this material in history textbooks for educational 